ECOLOGICA, Vol. 28, No 102 (2021), 250-256

https://doi.org/10.18485/ecologica.2021.28.102.16

Originalni naučni rad

UDC: 004.738.5:339]:502.131.1

\title{
Uticaj elektronske trgovine na životnu sredinu
}

\section{The impact of e-commerce on the environment}

\author{
Ljiljana Stanković ${ }^{1}$, Lazar Cvijić ${ }^{2 \star}$ \\ 1,2Univerzitet Union - Nikola Tesla, Fakultet za poslovne studije i pravo, Beograd, Srbija / \\ University Union - Nikola Tesla, Faculty of Business Studies and Law, Belgrade \\ *Autor za prepisku / Corresponding author
}

Rad primljen / Received: 21.12.2020, Rad prihvaćen / Accepted: 16.05.2021.

Sažetak: Elektronska trgovina danas poredstavlja neizostavan kanal prodaje za sve privredne oblasti. Njen dinamičan razvoj i dostignuti obim prodaje potakli su zabrinutost po pitanju uticaja na životnu sredinu. Kako bi se shvatio taj uticaj neophodno je analizirati i u potpunosti razumeti osnovne segmente u okviru lanca snabdevanja: pakovanje, transport, povraćaj i otpad.

Do sada sprovedena istraživanja potvrđuju da je online trgovina ekološki povoljnija opcija od kupovine i prodaje u tradicionalnim prodavnicama. Nema sumnje da ovakav način prodaje donosi brojne prednosti. Međutim, neophodno je poznavati i, ne tako zanemarljive nepoželjne efekte kako bi se moglo upravljati njima.

Ohrabruje činjenica da potrošači postaju sve svesniji i da sve više pažnje i poverenja poklanjaju trgovcima koji svoje logističke i druge aktivosti sprovode pokazujući visok nivo ekološke svesti. Sve intenzivnije uključivanje svesnih potrošača u kreiranje procesa, omogućavajući im da biraju i kreiraju opcije kupovine i isporuke proizvoda, vodi do višeg nivoa održivosti ovog, sve važnijeg, kanala maloprodaje. Sa druge strane ovo stvara pritisak na same proizvođače i trgovce da kreiraju upravo ekološki prihvatljivije modele poslovanja i time smanje, ili čak i preokrenu negativan ekološki uticaj.

Ključne reči: elektronska trgovina, potrošači, trgovci, životna sredina, ekologija.

\begin{abstract}
E-commerce today represents an unavoidable sales channel for all areas of the economy. Its dynamic development and the reached sales volume caused worry in regard to the impact on the environment. In order to understand this impact, it is crucial to analyse and fully understand the key segments in the supply chain: packaging, transport, returns, and waste. Research conducted up to now confirms that e-commerce is a more viable than shopping in the traditional stores. Moreover, it is certain that this way of sale brings numerous advantages. However, it is important to know its less neglectable effects so that they could be managed.

An encouraging fact is that consumers are becoming increasingly aware and that they are paying more attention to, and trusting those sellers which show a high ecological awareness throughout their logistics and other activities. The increasing incorporation of conscious consumers in the creation of processes, and allowing them to choose and create their buying and delivery options, leads to a higher level of sustainability of this increasingly important retail channel. On the other hand, this puts pressure on the producers and traders to create more ecologically acceptable business models, thereby reducing or even overturning the negative ecological impact.
\end{abstract}

Keywords: e-commerce, consumers, traders, environment, ecology.

${ }^{1}$ orcid.org/0000-0001-6465-4693, e-mail: lilijana.stankovic@fpsp.edu.rs

2orcid.org/0000-0003-2357-7489, e-mail: azar.cvijic@fpsp.edu.rs 


\section{UVOD / INTRODUCTION}

Trgovina, a posebno trgovina na malo, poslednjih decenija prolaze kroz istinsku trgovinsku revoluciju. Kao rezultat toga elektronska trgovina, jedan od načina tj. mogućnosti obavljanja kupovine, danas predstavlja neizostavan kanal marketinga za različite privredne oblasti. Upotreba online komunikacije, mobilnih uređaja, socijalnih mreža i slično promenili su zauvek poslovne modele prodavaca, ali i ponašanje kupaca.

Uzimajući u obzir dostignute, ali i svakim danom sve veće obime prodaje, počela su da se nameću pitanja uticaja ovog načina prodaje na životnu sredinu, iako od samog početka preovladava verovanje da je elektronska trgovina putem Interneta u ekološkom smislu održivija od tradicionalne. Zabrinutost za ekološku održivost elektronske trgovine, u početku je, u svom fokusu imala oblast logistike tj. isporuku proizvoda i usluga. Međutim, vremenom je porasla zainteresovanost, a u fokus su, sem logističkog sistema, dospeli i drugi segmenti aktivnosti. Počeli su da se javljaju uverljivi stavovi koji su dovodili u pitanje pretpostavljene ekološke benefite ovakvog načina trgovne, sugerišući da su negativni efekti, poput emitovanja gasova koji izazivaju efekat staklene bašte, otpada $\mathrm{i}$ upotrebe energije, potcenjeni.

U skladu sa rastućim sumnjama izdvojila su se četiri osnovna područja u okviru lanca snabdevanja koje treba osvetliti: pakovanje, transport, povraćaj robe i otpad. (Bertram i dr, 2018.) Do sada sprovedena istraživanja potvrđuju da je, uzimajući u obzir brojne okolnosti, online trgovina bolja za očuvanje životne sredine od kupovine i prodaje u tradicionalnim prodavnicama. Međutim, preterano pakovanje, insistiranje na bržoj isporuci, korišćenje komfornih mogućnosti povraćaja proizvoda i ogromne količine proizvoda koji se bacaju svakako povećavaju ugljenični otisak i zagađenje okruženja otpadom.

Kako informaciona tehnika i tehnologija svakodnevno sve više napreduju, elektronska trgovina postaje sve efikasnija i efektivnija, a prometi sve veći. Motivacija kupaca da kupuju elektronski u početku je bila prevashodno mogućnost uštede vremena, a danas oni postaju sve zahtevniji i svakodnevno žele da koriste sve više pogodnosti i to od različitih mogućnosti za isporuku do lakih i jednostavnih mogućnosti povraćaja kupljenih proizvoda.

$\mathrm{U}$ isto vreme, trgovci u svojoj borbi za opstanak na tržištu nastoje da izađu u susret promenjenim ponašanjima i zahtevima kupaca, jer je to jedini način da ostvare i zadrže prednosti u odnosu na konkurente. Razvoj digitalne tehnologije omogućio im je kreiranje i upotrebu modela u čijem središtu se nalaze kupci (potrošači). $U$ realnom vremenu prate i predviđaju njihove želje i rastuće potrebe, a nakon toga pronalaze načine kako da in zadovolje i kreiraju dugoročnu lojalnost kupaca. Nažalost, ovakvo ponašanje i jednih i drugih dovodi od toga da negativni efekti uticaja na životnu sredinu postaju sve više uočljivi. Industrija i proizvodi koji su najupečatljiviji u pogledu svega ovoga su, svakako, tekstilna industrija i tekstilni proizvodi.

$\mathrm{Na}$ jačanje prednosti elektronske u odnosu na tradicionalnu trgovinu u pogledu efekata na životnu sredinu svakako sve više treba da utiču percepcije i ponašanje samih e-kupaca. Ohrabruje činjenica da potrošači postaju sve svesniji i da sve više pažnje i poverenja počinju da poklanjaju trgovcima koji svoje logističke i druge aktivosti sprovode pokazujući visok nivo ekološke svesti. „Digital native“ $\mathrm{Y}$ generacija (milenijalci) veoma su samopouzdani kada koriste informaciono komunikacione tehnologije. Uglavnom veruju da je elektronska trgovina više prijateljska prema okruženju nego što je to tradicionalna sa svojim prodavnicama od "cigle i maltera“. Oni razumeju značaj i žele informacije o ekološkom uticaju njihovih nabavki. Spremni su da odaberu opciju dužeg čekanja na isporuku proizvoda ukoliko to podrazumeva „više ekološku“ isporuku. Čak šta više, veruju da bi ta opcija trebalo da se definiše kao uobičajena opcija, a da ukoliko žele bržu i „manje ekološku“ isporuku da za nju treba da plate dodatno. (Brunetti i dr. 2018.)

Elektronski trgovci su često virtuelne organizacije koje predstavljaju novi oblik organizacione strukture, u kojoj se za povezivanje ljudi, komunikaciju, ali i izvršavanje zadataka, pretežno koriste savremene digitalne tehnologije. (Džafić i dr., 2020.) Uz sve intenzivnije uključivanje svesnih potrošača u kreiranje procesa, omogućavajući im mogućnosti da biraju i kreiraju opcije kupovine $\mathrm{i}$ isporuke proizvoda, dolazi do višeg nivoa održivosti ovog sve važnijeg kanala maloprodaje. Sa druge strane ovo stvara pritisak na same proizvođače i trgovce da kreiraju ekološki prihvatljivije modele poslovanja i time smanje, ili čak i preokrenu negativan ekološki uticaj. Trgovci treba da budu usmereni da svoje konkurentske prednosti počnu da generišu upravo na ovim poljima.

\section{MATERIJALI I METODE / \\ MATERIALS AND METHODS}

Internet prodaja je oblik elektronske trgovine gde kupci i prodavci dolaze u kontakt putem elektronskog kanala komunikacije, koristeći globalnu računarsku mrežu za razmenu dobara i usluga te plaćanje. Ona se sada već u potpunosti poistovećuje sa elektronskom trgovinom zbog njenog preovlađujućeg učešća. Elektronska tj. Internet trgovina je jedan od kanala prometa koji se od 
samog nastanka nezadrživo i intenzivno razvija, a osebno snažan zamajac dobija sa nastankom pandemije Covid-19, 2020. godine. (llić i dr., 2020.)

Njenom razvoju snažno je doprinelo širenje mobilne telefonije, posebno smart mobilnih telefona sa stabilnim pristupom Internetu. Oni su omogućili komfornije i ugodnije sagledavanje ponude te sigurnije plaćanje. Pogodnosti mobilnog bankarstva tj. aplikacije za plaćanje preko pametnih telefona bili su dodatni podsticaj za pristupanje sve većeg broja potrošača ovim kanalima prometa. Pri tome ne treba zanemariti odnedavni intenzivni razvoj razvoj društvenih mreža i njihov doprinos podsticanju prodaje i odvijanju sveukupnih marketing aktivnosti. Ono što je bitno, sve ovo nije ograničeno granicama nacionalnih tržišta. Ponuda trgovaca dostupna je potrošačima iz raznih delova sveta.

Osim toga obavljanje trgovine, posebno trgovine na malo, elektronskim putem svakako jednostavniji i jeftiniji način od tradicionalnog obavljanja kupovine i prodaje. To je doprinelo da su virtuelni, elektronski načini prodaje počeli snažno da potiskuju tradicionalne. U skladu sa tim nije preterano tvrditi da će maloprodaja bliske budućnosti biti pretežno maloprodaja korisničke podrške, virtuelnih prodavnica, interaktivnosti, kupovine na kućnu adresu.

Ostvaren visok nivo razvoja elektronske trgovine potvrđuje i podatak o tome ko su trenutno najveći trgovci u svetu. U skladu sa podacima najvećeg svetskog udruženja trgovaca na malo National Retail Federation iz Vašingtona, SAD (National Retail Federation, 2020.) najveći trgovac na malo na svetu je Walmart. Međutim, ono što je značajno da odmah iza njega sledi najveći elektronski maloprodavac Amazon.com sa prometom od 232,88 milijardi dolara.

Prema izveštaju Global Ecommerce 2019, koji je publikovao eMarketer, ukupan maloprodajni promet ostvaren u 2019. godini u svetu na tradicionalan način dostigao je 25.038 milijardi \$ što podrazumeva povećanje do $4,5 \%$ u odnosu na prethodnu godinu. Sa druge strane, ukupan maloprodajni promet ostvaren u 2019. godini u svetu putem elektronske trgovine dostigao je 3.535 milijardi \$ što podrazumeva povećanje od $20.7 \%$ u odnosu na prethodnu godinu. (eMarketer, 2019) U skladu sa navedenim, korisno je naglasiti da je učešće elektronske maloprodaje u ukupnoj maloprodaji u 2019. godini u svetu bilo $14 \%$. Osim toga, pažnu privlače i razlike u stopama rasta pri čemu je stopa rasta elektronske trgovine u 2019. godini u odnosu na prethodnu bila skoro 5 puta veća nego stopa rasta tradicionalne maloprodaje.

Isti izveštaj daje prikaz prvih deset zemalja u svetu po ostvarenom maloprodajnom prometu elektronskim putem.

Tabela 1 - Prvih 10 zemalja u svetu rangiranih po ostvarenom maloprodajnom prometu elektronskim putem (milijardi \$)

Table 1 - Top 10 countries in the world ranged by e-commerce retail turnover (billions \$)

\begin{tabular}{|c|l|c|c|c|}
\hline Rang & Zemlja & $\mathbf{2 0 1 8 .}$ & $\mathbf{2 0 1 9 .}$ & \% promene \\
\hline 1 & Kina & 1520,10 & 1934,78 & $27,3 \%$ \\
\hline 2 & SAD & 514,84 & 586,92 & $14,0 \%$ \\
\hline 3 & Velika Britanija & 127,98 & 141,93 & $10,9 \%$ \\
\hline 4 & Japan & 110,96 & 115,40 & $4,0 \%$ \\
\hline 5 & Južna Koreja & 87,60 & 103,48 & $18,0 \%$ \\
\hline 6 & Nemačka & 75,93 & 81,85 & $7,8 \%$ \\
\hline 7 & Francuska & 62,27 & 69,43 & $11,5 \%$ \\
\hline 8 & Kanada & 41,12 & 49,80 & $21,1 \%$ \\
\hline 9 & Indija & 34,91 & 46,05 & $31,9 \%$ \\
\hline 10 & Ruska Federacija & 22,68 & 26,92 & $18,7 \%$ \\
\hline
\end{tabular}

Prema datom prikazu, najveće elektronsko tržište na svetu je tržište Kine, koje je u 2019. godini bilo tri puta veće od tržišta SAD-a, koje je na drugom mestu. $U$ tom momentu je na Kinu otpadalo $54,7 \%$ globalnog tržišta elektronske trgovine, skoro dvostruko više od ukupnog udela 5 narednih zemalja.
Pri tome je, tri od sedam najvećih elektronskih maloprodajnih tržišta locirano u Zapadnoj Evropi, gde je tržište Velike Britanije vodeće, a slede Nemačka i Francuska. Takođe, ne treba zapostaviti ni činjenicu da je najbrže rastuće tržište u svetu Indija sa stopom od oko $30 \%$. 


\section{REZULTATI I DISKUSIJA / RESULTS AND DISCUSSION}

\subsection{Uticaj elektronske trgovine na životnu sredinu / Impact of e-commerce on the environment}

Veoma dinamičan razvoj elektronske trgovine nameće i ozbiljne izazove koji dovode do zabrinutosti po pitanju uticaja na životnu sredinu. Mnogi smatraju da kupovina i prodaja na ovakav način ima, ukupno gledano, pozitivne efekte na životnu sredinu. Pre svega veruje se da se na ovaj način, usled izostanka putovanja kupaca do prodavnica, smanjuje emitovanje štetnih gasova i doprinos stvaranju efekta staklane bašte. Takođe, smatra se da pozitivnim efektima doprinosi i izostanak postojanja tradicionalnih prodajnih objekata od "cigle i maltera" i u tom smislu upotrebe energije i ostalih negativnih uticaja na okruženje. Međutim, situacija u stvarnosti je dosta kompleksnija. Elektronska trgovina nije bez negativnih uticaja na životnu sredinu.

Inače, lanac snabdevanja za elektronski i tradicionalni način trgovanja sa prodajnim objektima je strukturiran veoma slično, sve dok se ne dođe do poslednje faze distribucije tj. isporuke proizvoda kupcima. Trgovci, i jedni i drugi, dovoljno vremena unapred vrše poručivanje robe od svojih dobavljača, koja kada je pribavljena ili proizvedena biva transportovana u skladište trgovca. U slučaju tradicionalnog načina bitno je da ta skladišta budu locirana u blizini što više trgovaca na malo i njihovih prodavnica. Kasnije kupci odlaze do prodavnica, kupuju proizvode i vraćaju se kući sa njima.

Elektronski trgovci ne moraju da imaju centralno locirane skladišta, jer će se njihovi proizvodi i onako slati na razne lokacije širom zemaljske kugle. Kada distributivni centar primi porudžbine, pribavljene od kupaca prevashodno elektronskim putem, one će se pojedinačno procesuirati, proizvodi će se pakovati u traženim količinama i pojedinačne pošiljke če se slati putem poštanskih i kurirskih službi na adresu kupca. To pakovanje i transport proizvoda od skladišta do konačnog odredišta naziva se „poslednja milja“ (last mile), i upravo je ona najčešće u fokusu analize uticaja same elektronske trgovine na životnu sredinu. "Poslednja milja" se zbog specifičnosti procesa razlikuje od porudžbine do porudžbine, od kupca do kupca i samim tim različito utiče i na okolinu.

U ovom trenutku najviši nivo svesti i zabrinutost, sem pitanja transporta, postoji po pitanju otpada od ambalaže proizvoda koji se preko poštanskih i kurirskih službi dostavljaju od strane prodavca kupcu. Tipična pošiljka elektronske trgovine može da koristi i do sedam vrsta ambalažnih materijala: papirne račune, koverte, kartonske kutije, plastične kese, tkane kese, trake za lepljenje i vezivanje, i „tampon“ mateijale (folija sa vazdušnim mehurićima, stiropor). (Chueamuangphan i dr., 2019.) Kupci žele što viši nivo ugodnosti i sigurnosti kupovine i retko kritikuju „prekomernu“ ambalažu iako sve te materijale za pakovanje jednostavno i bez mnogo razmišljanja bacaju na otpad.

Međutim, sem negativnih efekata transporta i ambalaže, logističkih procesa neopodnih da se isporuče proizvodi i usluge poručeni od strane kupaca, postoje i brojni drugi segmenti na koje je neophodno obratiti pažnju. U prvom redu to je oprema iz oblasti informaciono komunikacione tehnologije koja omogućava odvijanje elektronskog trgovanja. Nakon toga, nikako ne bi trebalo zanemariti ni značajne količine robe koja se vraća trgovcima od strane kupaca, čemu intenzivno doprinose propisi koji omogućavaju da se svaki proizvod kupljen na ovaj način u roku od 15 dana može da vrati trgovcu bez ikakvog obrazloženja. I na kraju, kako elektronska trgovina podstiče ubrzanu kupovinu i zamenu proizvoda, ne treba zanemariti ni ogromne bačene količine proizvoda koje bi još uvek mogle biti u upotrebi.

Najupečatljiviji primer za sve ovo je odeća. Elektronska trgovina je dramatično promenila način kupovine odeće. Pre trideset ili četrdeset godina postojale su samo dve modne sezone: proleće-leto i jesen-zima. Danas ne postoje sezone. Doslovno se svakodnevno potrošačima nude novi trendovi i novi proizvodi. Zahvaljujući masovnim komunikacijama i lakom pristupu informacijama širom sveta proizvođači i trgovci brzo i lako prikupljaju informacije o kretanjima na tržištu i željama kupaca. U skladu sa njima u vrlo kratkom vremenu proizvode jeftinu odeću, koja veoma često oponaša postojeće luksuzne modne trendove, i prodaju je potrošačima online. $\mathrm{Na}$ ovaj način, mogućnost elektronske prodaje ogromnih količina jefine odeće ove „brze mode“ realizovale su džinovske svetske kompanije poput Zare, H\&M, TJX (diskontni lanac garderobom TK Maxx prodavnica) i slično, koje spadaju u najveće prodavce na svetu. One su time dalje još više pojeftinile i olakšale kupovinu odeće. Što potrošači jeftinije i lakše kupuju odeću, to je kupuju, ali i bacaju, u većim količinama. Nažalost, konačan rezultat je ogromna količina otpada sa veoma negativnim efektima po naše životno okruženje.

Otpad je samo jedan od segmenata koji, u okviru industrije odeće, negativno utiče na životnu sredinu. Odeću koja se prodaje u ovako ogromnim količinama potrebno je, prethodno, bezbedno transportovati do kupca, što podrazumeva i adekvatnu ambalažu. Logističke aktivnosti i pakovanje značajno doprinose većem ugljeničkom otisku svakog pojedinačnog proizvoda, čemu treba dodati i post- 
prodajno ponašanje potrošača (njegove odluke $u$ pogledu povraćaja proizvoda ili bacanja).

Očito je da se svi pomenti faktori moraju analizirati i razumeti u potpunosti kako bi se shvatio uticaj elektronske trgovine na životnu sredinu. Prioritetno su to: pakovanje, transport, povraćaj i bacanje proizvoda.

Pakovanje ima dve osnovne namene. Jedna je da smanji rizik od oštećenja i da omogući da proizvod ispravan stigne na adresu kupca. Druga je dalja promocija proizvoda, nastavak oglašavanja i dalje utemeljenje prepoznatljivosti brenda. Iz tog razloga izgled i kvalitet pakovanja je veoma bitan iz ugla realizacije marketing strategije i razvoja imidža brenda kompanije i proizvoda. Osim toga, kupci procenju „vrednost“ prodavca na osnovu pakovanja. Veruju da pakovanje odražava njihov pristup ka potrošačima, smatrajući da kvatitet i količina materijla pokazuje koliko im je stalo i koliko ulažu napora da zaštite proizvod kako bi on stigao bezbedno do vrata kupca. Nažalost, pakovanje pokreće brojna otvorena pitanja i zabrinutost jer stvara ogromne količine otpada.

Za pakovanje online poručenih proizvoda koriste se pretežno kartonske kutije koje zahtevaju mnogo veću emisiju $\mathrm{CO}_{2}$ nego plastične kese koje se koriste za kupovinu u prodavnicama i koje se mogu koristiti više puta. Smatra se da je tražnja za kartonskim kutijama za pakovanje proizvoda za sektor elektronske trgovine jedna od najbrže rastućih tražnji za proizvodima trenutno. Međutim, proizvodnja kartonski kutija koje je u potpunosti moguće reciklirati i njihovo recikliranje nije rešenje pošto i to podrazumeva određeni uticaj na okolinu i ostavlja određeni ugljenični otisak.

Fizička distribucija podrazumeva sve aktivnosti koje omogućavaju kretanje proizvoda od mesta proizvodnje do mesta isporuke konačnom kupcu. Te aktivnosti podrazumevaju skladištenje i upravljanje zalihama, prodaju, a posebno transport. Zbog zahteva kupaca da isporuka bude izvršena u što kraćem roku (obično u roku $24 \mathrm{~h}$ ) prodavci koriste brža i skuplja sredstva transporta koja destruktivno deluju po okruženje. Takođe, zahtevi da se roba isporuči tačno na vrata kupca doprinose izraženijim negativnim efektima elektronske trgovine. Isporučujući „od vrata do vrata" dostavna vozila prelaze značajniji broj kilometara pri čemu troše više energije i ispuštaju veće količine štetnih gasova.

Sa druge strane, kada su u pitanju tradicionalna trgovina i kupovina u prodavnicama, sem transportnih napora i troškova na strani ponude, potrebni su i oni na strani kupca. Svakako je potrebno da kupac dođe do prodavnice da bi obavio kupovinu i vratio se s proizvodom kući, što ima svoje negativne efekte.

Očito je ispred nas zahtev da se istraže i uporede troškovi transporta jednog i drugog načina kupovine, njihova isplativost i ekološki uticaj. Postojeća istraživanja do određene udaljenosti potrošača od prodajnog objekta daju prednost kupovini $u$ maloprodajnim objektima, a kako se udaljenost potrošača povećava prednost prelazi na stranu elektronskog obavljanja kupovine. Prikupljanje znanja i kreranje modela za upravljanje po ovim pitanjima u monogme bi pomogli donosiocima odluka koji brinu o zaštiti životne sredine, ali i samim trgovcima. Osim toga, svesniji potrošači pravili bi i racionalnije izbore jer je to svakako u njihovim interesu.

U okviru transporta interesantno je i pitanje "neisporučenih" pošiljki kada nikog nema na adresi u momentu prispeća pošiljke ili kada se zahteva prijem od strane kupca lično. Procenat neisporučenih pošiljki se sve više povećava zbog sve većeg broja samačkih domaćinstava i onih gde su oba partnera zaposlena. Zavisno od politike poštanskog operatora paket se vraća kako bi se ponovni pokušaj uručivanja obavio sledećeg radnog dana. Uspešne i neuspešne isporuke imaju različite efekte u smislu efekata na životnu okolinu, potrošnje energije i emisije štetnih gasova.

Procenat povraćaja prozvoda se razlikuje do vrste do vrste proizvoda. Faktori koji utiču na to su svakako oni po čemu je elektronska trgovina prepoznatljiva: nemogućnost da se proizvod fizički vidi, oseti i proba pre poručivanja. Iz tih razloga, veoma često, tek kada proizvod stigne kupac uvidi problem u pogledu izgleda, veličine ili kvaliteta proizvoda. Elektronski trgovci su svesni toga, i u cilju zadržavanja kupaca i povećavanja njihovog broja, omogućavaju veoma jednostavne i ugodne povraćaje. Veliki broj trgovaca plaća troškove isporuke ili povraćaja proizvoda, ili čak i jedne i druge. Sve to u značajnoj meri povećava količine vraćenih proizvoda i zahteva brojne logističke napore kako bi se proizod vratio "uzvodno" uz lanac snabdevanja ili "eliminisao".

Za životnu sredinu najmanje štetan način je da poštanski operator, u okviru svojih uobičajenih ruta, izvrši i preuzimanje proizvoda koje kupci žele da vrate. Sa druge strane, najmanje povoljna opcija je da kupac sam odlazi na fizičke lokacije maloprodavca kako bi vratio proizvod, jer to podrazumeva ogroman broj pojedinačnih putovanja do prodavnice i nazad.

Savremeno potrošačko društvo svara ogromne količine otpada. Danas se češćim kupovinama od realno potrebnih, veoma često zadovoljavaju emocionalne i socijalne potrebe. To je posebno slučaj kod 
kupovine odeće, kada "brza moda" omogućava da se uklopite u svoje socijalno okruženje i ostanete u toku sa stalno menjajućim trendovima. Mlađe generacije više prihvataju promenljive trendove, radije kupuju jeftinije proizvode, za nekoliko meseci ih bacaju i kupuju nove, a stariji žele da imaju manji broj, kvalitetnijih proizvoda.

Većina otpada tekstilnih proizvoda nastaje zahvaljujući matrici "brze mode" koja kombinuje dva elementa: brzu i jeftinu proizvodnju i isporuku sa planiranim zastarevanjem proizvoda koje podrazumeva da se artikli i dizajniraju da kratko traju i da se nakon toga bacaju i zamenjuju sa novijim proizvodom. Na taj način ogromne količine otpada po glavi stanovnika završavaju na deponijama. A veće količine otpada znače i više emisije metana i značajnije zagađenje podzemnih voda.

U svakom slučaju, jasno je da uticaj razvoja elektronske trgovine na životnu sredinu nije tako beznačajan. Brojni su segmeti aktivnosti koje je, u tom smislu, neophodno definisati i detaljnije istražiti. Nema sumnje da ovakav način prodaje donosi brojne prednosti, ali je neophodno poznavati i negativne, nepoželjne efekte, pre svega na životnu sredinu kako bi se moglo upravljati njima. A trgovina svakako ostavlja mnogo prostora za to i svoj fokus usmerava na "ozeljenjavanje" lanca snabdevanje koje podrazumeva proces upravljanja kojim proizvođači, kupci i trgovci smanjuju svoj uticaj na životnu sredinu u lancu vrednosti. (Pavićević i dr., 2020.)

\subsection{Mogućnosti smanjenja negativnih efekata elektronske trgovine na životnu sredinu / Possibilities of reducing the negative effects of e- commerce on the environment}

$\mathrm{Na}$ savremenim tržištima razvijenih zemalja potrošači postaju sve više svesni i zabrinuti za očuvanje životne sredine i posledice svojih postupanja. Uporedo sa tim oni počinju da prave pritisak na proizvodne i trgovinske kompanije da svoja ponašanja koriguju u pravcu višeg nivoa održivosti. Ovakav pritisak dolazi i od akcionara, članova poslovnih udruženja i same države. Interesantan je revolucionarni primer poslovnog udruženja Sustainable Apparel Coalition. Ono okuplja vodeće kompanije iz tekstilne i industrije obuće sa ciljem razmene informacija o strategijama održivog poslovanja i procene njihovog uticaja na životnu sredinu koristeći The Higg Index koji su razvili 2016. godine. Zahvaljujući tome sposobni su da pokreću socijalne i ekološke promene i poboljšanja koje u ovoj grani industrije treba da postanu održiva. (Sustainable Apparel Coalition, 2020.)

Da bi se smanjili negativni efekti elektronske trgovine na životnu sredinu, pre svega, neophodno je da elektronski trgovci prodaju proizvode i usluge koji imaju najmanje moguće ekološke uticaje. Kada je pakovanje u pitanju prevashodno je potrebno koristiti reciklirani karton i papir za pakovanje (kese) kako bi eliminisali plastiku u ovom koraku. U tom smislu, veoma korisna su efektna uputstva i politike u cilju izbegavanja preterane upotrebe materijala za pakovanje. Dalje, 3D štampa predstavlja polje koje je potrebno usavršavati u smislu mogućnosti štampanja ambalaže. Takva ambalaža bi bolje pratila oblik i veličinu proizvoda i zahtevala bi manje količine materijala. Proizvodnja bi bila čistija, sa manjim emitovanjem $\mathrm{CO}_{2}$, efikasnija i jeftinija. (Escursell $\mathrm{i}$ dr., 2020.)

Kada je u pitanju transport, dostavne službe treba da koriste vozila na električni i hibridni pogon ili biogas (prirodni gas, propan, etanol, biometan...). Takođe, ogroman doprinos daju i softveri za planiranje ruta koji definišu naj efikasnije rute koje će smanjiti vreme vožnje, uštedeti novac i, svakako, smanjiti negativne ekološke efekte. $U$ tom smislu značajno je pomenuti tehnološki uspešan razvoj isporuke paketa dronovima. Dronovi će eliminisati tj. umanjiti potrebu za vozilima i kamionima koja se kreću ka i od adrese kupca. Koristiće baterije tako da neće izazvati ni približno zagađenje kao dostavna vozila, a posebno će se smanjiti zagađenje koje nastaje tokom "poslednje milje" isporuke. Takođe zahtevaće i promenu oblika paketa i upotrebu novih, lakših, održivih materijala.

Osim toga razvijaju se brojna druga tehnološka rešenja koja će da unaprede proces transporta i isporuke. Jedno od njih su sistem (Amazona) posebnih elektronskih brava i kamera za praćenje koji omogućava da dostavljači samostalno ulaze u stanove i ostavljaju proizvode (čak i frižidere kupaca ukoliko se radi o hrani) kada niko nije prisutan na adresi kupca. Mada su sve češći automatizovani "paket automati", mesta za lično preuzimanje paketa, postavljeni u urbanim regijama.

Kompanije koje se bave elektronskom prodajom nastoje da kreiraju i usvoje tehnologije koje će unaprediti sa jedne strane iskustvo potrošača tokom kupovine, a sa druge strane efikasnost poslovanja. Primer su softveri koji počinju da ulaze u upotrebu, a koji omogućavaju potrošačima da "vide" kako će im pristajati određeni odevni predmet. Oni upoređuju mere proizvode koje potršači već poseduju sa onima koje potrošači žele da kupe. Na taj način dovode do kvalitetnijih odluka po pitanju veličine i konačno do mnogo manje vraćenih proizvoda.

Količinu otpada značajno mogu da smanje recikliranje, doniranje, prenamena, organizovanje lične prodaje polovnih stvari i "second-hand" prodaje. Jedan od najpoznatijih sajtova za prodaju polovne odeće u svetu je online platforma Poshmark. Sem web sajta poseduju i aplikaciju za mobilne telefone 
uz pomoć koje korisnici mogu veoma lako da učitaju svoju ponudu za prodaju. Svakodnevno se preko ove platforme ponudi ogroman broj proizvoda i obavi ogroman broj transakcija.

Modna kompanija Reformation ide jedan korak dalje i šalje svojim kupcima, zajedno sa poručenom robom, kutiju sa etiketom za slanje nazad starih, nošenih, proizvoda. Na ovaj način oni koji žele da recikliraju mogu da doprinesu životnoj sredini bez da ulažu dodatne napore. Takođe, Reformation je dobar primer ekološki orijentisane kompanije koja na svom sajtu daje iscrpne informacije o svojm proizvodima, za koje opet nastoje da budu ekološki što prihvatljiviji. Osim toga daju iscrpne kvatralne raporte u kojima navode pomake koje čine u uštedi $\mathrm{CO}_{2}$, uštedi vode i otpadu koji generišu, a kao cilj do 2021. godine definisali su $100 \%$ ugljeničnu neutralnost. Sav trud o kome na ovaj način informišu potrošača na kraju opravdava nivo cena po kojima nude svoje proizvode..

\section{ZAKLJUČAK / CONCLUSION}

lako ekološki efekti trgovine koja se obavlja posredstvom Interneta već intenzivno privlače pažnju, nedostaje znanja, ozbiljnih istraživanja i predloga za prevazilaženje postojeće situacije. Sve je dosta komplikovano pošto elektronska trgovina u određenim segmentima smanjuje štetne posledice, a opet $u$ drugim područjima ih povećava. Stalna je debata da li je elektronska trgovina čista tehnologija pošto umanjue korišćenje resursa, ili je upravo suprotno jer ubrzava tražnju za resursima.

Očito je neophodno sprovesti brojna istraživanja kako bi se došlo do jednoznačnih i celovitih saznanja i zaključaka po pitanju uticaja tj. elektronske trgovine na životnu sredinu. Potrebno je da ta sveobuhvatna istraživanja obuhvate primarne, sekundarne i tercijarne efekte tj. efekte opreme koja se koristi za implementaciju sistema informacione tehnologije kao što su računari i telefoni, efekte prevoza, pakovanja i slično te efekte postprodajnog ponašanja potrošača (povraćaj ili bacanje proizvoda).

Cilj u budućnosti, uporedo sa rastom učešća elektronske prodaje, biće transformacija elektronske trgovine $u$ "zelenu trgovinu“. U skladu sa tim neophodna će biti ulaganja trgovinskih kompanija u inovacije ambalaže i održivo funkcionisanje sistema lanca snabdevanja. Cilj će biti opšte prihvatanje ponovne upotrebe i reciklaže, ali i promena ponašanja potrošača u potrošnji. Neophodno će biti usvajanje novih tehnologija i promocija ideja korporativne društvene odgovornosti i ekološke održivosti proizvoda i procesa.

\section{LITERATURA / REFERENCES}

[1] Bertram R.F., Chi T. (2018), A study of companies' business responses to fashion e-commerce's environmental impact, International Journal of Fashion Design, Tehnology and Education, 11(2), 254-246. https://www.tandfonline. com/doi/full/10.1080/17543266.2017.1406541

[2] Brunetti F., Russo I., Confente I. (2018), How Environmentally Freindly is E-Commerce? An Exploration into Young Shoppers' Perceptions and Preference, Excellence in Services, 21th International Conference, Proceedings, 105-112.

[3] https://www.researchgate.net/publication/331088 705_How_Environmentally_Friendly_is_ECommerce_An_Exploration_into_Young_Shopp ers'_Perceptions_and_Preferences

[4] Chueamuangphan K., Kashyap P., Visvanathan C. (2019), Packaging Waste from E-commerce: Consumers' Awareness and Concern, Sustainable Waste Management: Policies and Case Studies - Conf. Proceedings, Vol. 1, 27-41. https://link.springer.com/chapter/10.1007/978981-13-7071-7_3

[5] Džafić G., Ristić Z., Bilal Z.M.A., Alshibani W.M.S., Damjanović M.A. (2020), Digitalizacija ekonomije: uticaj na tržište rada i zaposlenost, Ecologica, 27 (100), 633- 639.

[6] eMarketer, (2019). Report: Global Ecommerce 2019, https://www.emarketer.com/content/globalecommerce-2019

[7] Escursell S., Llorach-Massana P., Blanca Roncero M. (2020), Sustainability in e-commerce packaging: A review, Journal of Cleaner Production, 280(1), doi.org/10.1016/j.jclepro.2020.124314

[8] Ilić T. D., Cvijić Lj. i Stanković Lj. (2020), Alternative Scenarios for the Exit of the Global Economy From the Recession Caused by the Covid-19 Pandemic With a Special Focus on Ecommerce, International thematic proceedings: Covid-19 Pandemic Crisis Management a Nonmedical Approach, Belgrade, Serbia, 111-133.

[9] National Retail Federation, NRT, (2020). Top 50 Global Retailers 2020, https://nrf.com/resources/top-retailers/top-50global-retailers/top-50-global-retailers-2020

[10] Pavićević A., Vuković A. i Cvijić L. (2020), Ekološki aspekti lanca snabdevanja - pojam „ozelenjavanja", Ecologica, 27(100), 655-663.

[11] Sustainable Apparel Coalition, 2020, www.apparelcoalition.org. 